\title{
Projected soil organic carbon loss in response to climate warming and soil water content in a loess watershed
}

\author{
Fubo Zhao ${ }^{1}$, Yiping $\mathrm{Wu}^{1^{*}} \mathbb{C}^{0}$, Jinyu Hui ${ }^{1}$, Bellie Sivakumar ${ }^{2}$, Xianyong Meng ${ }^{3}$ and Shuguang Liu ${ }^{4}$
}

\begin{abstract}
Background: Soil organic carbon (SOC) plays a crucial role in the global carbon cycle and terrestrial ecosystem functions. It is widely known that climate change and soil water content (SWC) could influence the SOC dynamics; however, there are still debates about how climate change, especially climate warming, and SWC impact SOC. We investigated the spatiotemporal changes in SOC and its responses to climate warming and root-zone SWC change using the coupled hydro-biogeochemical model (SWAT-DayCent) and climate scenarios data derived under the three Representative Concentration Pathways (RCPs2.6, 4.5, and 8.5) from five downscaled Global Climate Models (GCMs) in a typical loess watershed--the Jinghe River Basin (JRB) on the Chinese Loess Plateau.

Results: The air temperature would increase significantly during the future period (2017-2099), while the annual precipitation would increase by $2.0-13.1 \%$ relative to the baseline period (1976-2016), indicating a warmer and wetter future in the JRB. Driven by the precipitation variation, the root-zone SWC would also increase (by up to $27.9 \%$ relative to the baseline under RCP4.5); however, the SOC was projected to decrease significantly under the future warming climate. The combined effects of climate warming and SWC change could more reasonably explain the SOC loss, and this formed hump-shaped response surfaces between SOC loss and warming-SWC interactions under both RCP2.6 and 8.5, which can help explain diverse warming effects on SOC with changing SWC.

Conclusions: The study showed a significant potential carbon source under the future warmer and wetter climate in the JRB, and the SOC loss was largely controlled by future climate warming and the root-zone SWC as well. The humpshaped responses of the SOC loss to climate warming and SWC change demonstrated that the SWC could mediate the warming effects on SOC loss, but this mediation largely depended on the SWC changing magnitude (drier or wetter soil conditions). This mediation mechanism about the effect of SWC on SOC would be valuable for enhancing soil carbon sequestration in a warming climate on the Loess Plateau.
\end{abstract}

Keywords: Carbon cycle, Climate change, Soil organic carbon, Soil water content, SWAT-DayCent

*Correspondence: rocky.ypwu@gmail.com

${ }^{1}$ Department of Earth \& Environmental Science, School of Human

Settlements and Civil Engineering, Xi'an Jiaotong University, Xi'an 710049, Shaanxi, China

Full list of author information is available at the end of the article

\section{Background}

Soil is the largest carbon (C) reservoir and stores about $1505 \mathrm{Pg} \mathrm{C}$ in the top one meter, approximately twice as much the amount in the atmosphere or three times in the terrestrial vegetation [1-3]. Soil organic carbon (SOC) forms the majority of the terrestrial soil $\mathrm{C}$ pool (accounting for nearly $62 \%$ of the soil carbon pool) and plays an important role in the global $\mathrm{C}$ cycle and balance [4-6]. Even a small change in the SOC can substantially affect original author(s) and the source, provide a link to the Creative Commons licence, and indicate if changes were made. The images or other third party material in this article are included in the article's Creative Commons licence, unless indicated otherwise in a credit line to the material. If material is not included in the article's Creative Commons licence and your intended use is not permitted by statutory regulation or exceeds the permitted use, you will need to obtain permission directly from the copyright holder. To view a copy of this licence, visit http://creativecommons.org/licenses/by/4.0/. The Creative Commons Public Domain Dedication waiver (http://creativeco mmons.org/publicdomain/zero/1.0/) applies to the data made available in this article, unless otherwise stated in a credit line to the data. 
not only the climate but also the stability of ecosystems, because of its decisive role in the exchange of carbon between the soil and atmosphere and plant growth/food production [7-10]. Therefore, understanding the spatiotemporal changes of SOC and the associated driving factors is of critical importance to evaluate the feedbacks between terrestrial $\mathrm{C}$ cycle and climate change and the maintenance of the ecosystem functions [11-13].

Whether soil $\mathrm{C}$ pool acts either as a source or as a sink for atmospheric $\mathrm{CO}_{2}$ is largely controlled by the changes in climate and soil water content (SWC) [14-20]. Climate change, especially climate warming, can directly or indirectly impact the SOC decomposition through controlling the soil microbes, enzyme activities, and soil respiration [21]. During the past several decades, although many studies have examined the effects of climate warming on the SOC dynamics, there are still debates on this issue due to the contradictory results reported [3, 22]. Some modeling studies and meta-analysis showed that climate warming could stimulate the loss of soil $\mathrm{C}$ into the atmosphere because of the stronger warming effects on respiration than photosynthesis, leading to positive land C-climate feedback [23-26]. For example, through compiling data from the published literature, Crowther et al. [7] found that climate warming could remarkably reduce the SOC stocks and the warming effects were largely contingent on the size of the initial SOC stocks. Using a biogeochemical model, Zhao et al. [11] found that SOC would significantly decrease under a warming climate in a typical loess hilly and gully watershed. In contrast, results from some experimental studies showed that warming could also stimulate the carbon uptake in some ecosystems, leading to negative C-climate feedbacks [27-29]. For example, Zhang et al. [28] found that the temperature rise might enhance the $\mathrm{CO}_{2}$ sink in both boreal and temperate ecosystems. Some global-scale studies have also revealed that the warming effects on the SOC decomposition might be overestimated because the SOC decomposition rates were remarkably constant across the mean annual temperature gradient [29]. These contradictory results suggest that the relationship between climate warming and the SOC dynamics and the C-climate feedbacks remain uncertain, thus constraining the accurate prediction of the future climate change.

Soil water content is another important factor driving the SOC dynamics. It is generally known that SWC plays a crucial role in vegetation growth and $C$ substrate supply for microbial activities under different climate conditions $[30,31]$. High SWC may stimulate the $C$ uptake (e.g., the ecosystem productivity) or release it (e.g., the soil respiration) in a warm climate, but excessive SWC could depress them in relatively wet climate conditions [32-34]. For example, in cool tropical forests, high water availability can slow the $\mathrm{C}$ cycling, while in warm tropical forests it can enhance the ecosystem productivity and SOC decomposition [32]. In the arid and semi-arid steppes, high SWC can accelerate the soil respiration rate, leading to a significant C loss from soil [35]. The SWC also plays a crucial role in controlling the responses of $\mathrm{C}$ cycle to climate warming [36]. The warming effects on $C$ would flip from positive to negative as the soil changes from wet to dry, demonstrating the key role of SWC on warminginduced C gain or loss [37]. A recent study revealed that warming could stimulate net carbon uptake under wet conditions but depress it under very dry conditions [27]. These findings suggest that the $\mathrm{C}$ cycle is closely linked with SWC, and this relationship could be more complex under climate warming. Furthermore, in the context of climate change, shifts in soil water caused by precipitation will continuously exert uncertain influences on the future $\mathrm{C}$ dynamics. Moreover, it is still not clear how climate warming and SWC interact with each other to impact the SOC dynamics at watershed or regional scale, which largely hampers the modeling and projections of the global C cycling.

The overall goal of this study was to investigate the spatiotemporal changes in SOC and its responses to future changes in climate and SWC in a loess watershed. To this end, the Jinghe River Basin (JRB), a large typical loess hilly-gully watershed on the Loess Plateau, was studied. A coupled hydro-biogeochemical modelSWAT-DayCent-combined with projections from five downscaled Global Climate Models (GCMs) (GFDLESM2M, HadGEM2-ES, IPSL-CM5A-LR, MIROC-ESMCHEM, and NoerESM1-M) under three Representative Concentration Pathways (RCPs) (RCP2.6, RCP4.5, and RCP8.5) was used. Specifically, we aimed to: (1) investigate the spatiotempral changes in SOC and SWC under current (1976-2016) and projected future climate scenarios (2017-2099), and (2) examine the responses of SOC to both climate warming and SWC change in the JRB.

\section{Methods}

\section{Study area}

The Jinghe River Basin $\left(106^{\circ}-108^{\circ} \mathrm{E}, 34^{\circ}-37^{\circ} \mathrm{N}\right)$ is a typical loess hilly-gully watershed located in the southern part of the Chinese Loess Plateau (Fig. 1). The Jinghe River originates from the Liupan Mountain and has a total length of $455 \mathrm{~km}$ [14]. The watershed lies in the semi-humid and semi-arid transitional zone with a typical continental climate [38]. The annual average precipitation and temperature are about $350-600 \mathrm{~mm}$ and $8-13{ }^{\circ} \mathrm{C}$ (from north to south), respectively, and approximately $80 \%$ of precipitation occurs in the flood season between July and September. Grassland, cropland, and 


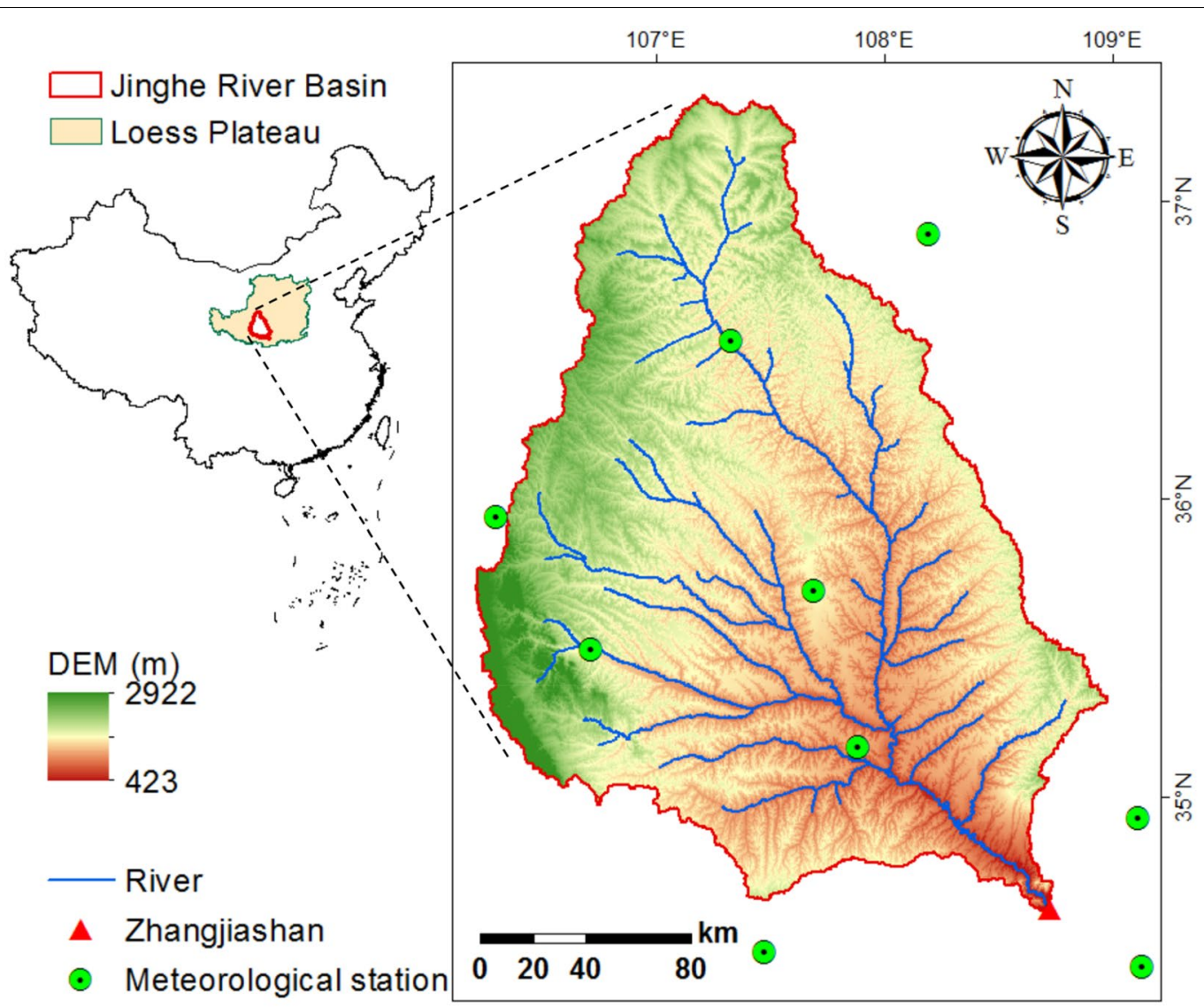

Fig. 1 Location and DEM of the Jinghe River Basin. The red triangle indicates the Zhangjiashan Gaging station and the green circles indicate the meteorological stations

forest are the major land use types in the basin, accounting for $90 \%$ of the total area [39]. The watershed is often subject to severe water shortage and soil erosion due to the dry climate and loosened land surface.

\section{Description of SWAT-DayCent}

The SWAT-DayCent model, coupled from the widelyused watershed-scale distributed hydrological model (Soil and Water Assessment Tool, SWAT) [40] and the principle biogeochemical model (daily time step version of the CENTURY model, DayCent) [41, 42], was developed by Wu et al. [43]. It can simultaneously simulate the hydrological and biogeochemical processes at the watershed scale. In the coupled running process, the SWAT was set as the basic framework and the DayCent was embedded into SWAT at the HRU (Hydrologic Response Unit) level, together with some new functions for information transfer and format conversion. For example, some functions were used to change the soil structure to meet DayCent requirement and transform the soil property information in each HRU into DayCent. The major watershed-scale outputs of SWAT-DayCent include hydrological components (e.g., streamflow, soil water, ET) produced by SWAT and biogeochemical components (e.g., NPP (Net Primary Productivity), SOC, soil respiration) produced by DayCent, enabling users to integrate the modeling of water and carbon at the same spatiotemporal input and at the same computing units, facilitating the analysis of interaction between water and carbon at the watershed scale. In DayCent simulations, the SOC model simulates SOC dynamics for three SOC pools-soil active, slow, and passive pools. The active pool includes soil microbes and microbial products with short turnover times (1-3 months), the slow SOC pool includes resistant plant material that have turnover times ranging from 10 to 50 years depending on climate, and the passive pool includes physically and chemically stabilized SOC that is very resistant to decomposition [44]. The decomposition of SOC is microbially-mediated with an associated microbial respiration $\mathrm{CO}_{2}$ loss. Each SOC pool has specific maximum decomposition rates with maximum being reduced by an abiotic soil decomposition factor that is controlled by the soil moisture and soil temperature. In addition, the SOC decomposition is also largely 
controlled by soil texture. For example, the net effects of the soil texture on active and slow SOC decomposition is to increase soil carbon stabilization for soils with low sand content and high clay content. Extensive details of the development and applications of SWAT-DayCent can be found in our previous studies [11, 12, 43, 45].

\section{Model input and verification}

The ArcSWAT (version 2012) was employed in this study to automate the input parameters. The required inputs for SWAT include topography, land use, soil type, and meteorological information. The digital elevation model (DEM) was obtained from the Shuttle Radar Topography Mission (SRTM) with a 90-m resolution to delineate the watershed and define the stream networks. The land use and soil property data were obtained from the Ecological and Environmental Science Data Center for West China with a $1-\mathrm{km}$ resolution. The historical daily meteorological data, including precipitation, maximum and minimum temperature, relative humidity, wind speed, and sunshine duration, were obtained from the data center of China Meteorological Administration (CMA), covering the study period from 1976 to 2016 . The sunshine duration here was used to calculate the solar radiation required for SWAT [39].

As in our previous studies [12, 14, 45], the SWATDayCent was calibrated and validated for performance in hydrological and carbon cycle simulations by using the monthly streamflow from the Zhangjiashan station (see its location in Fig. 1) and remotely-sensed NPP. The use of multiple criteria performance evaluation measures, including NSE (Nash-Sutcliffe Efficiency), $\mathrm{R}^{2}$ (correlation coefficient), PB (percentage bias), and RMSE (root mean square error), showed that the SWAT and DayCent could simulate the water and carbon cycles with satisfactory performance [46]. Details of the calibration and validation schemes and the model performance can be found in our previous publications $[12,14,45]$.

\section{Future climate datasets}

In this study, we used the future climate datasets (precipitation and maximum/ minimum air temperature) that were downscaled from five GCMs (GFDL-ESM2M, HadGEM2-ES, IPSL-CM5A-LR, MIROC-ESM-CHEM, and NoerESM1-M (Table 1)) by the Inter-Sectoral Impact Model Inter-comparison Project (ISI-MIP) under Representative Concentration Pathway (RCP) 2.6 (low emission pathway), RCP4.5 (low-to-moderate emission pathway), and RCP8.5 (high emission pathway) [47, 48]. Unlike the Coupled Model Inter-comparison Project Phase 5 (CMIP5), the data sets from ISI-MIP were bias-corrected by comparing with the Climatic Research Unit (CRU) data and downscaled to $0.5^{\circ} \times 0.5^{\circ}$ spatial resolution [49]
Table 1 Information of the five global climate models (GCMs) used in this study

\begin{tabular}{|c|c|c|}
\hline Model & $\begin{array}{l}\text { Resolution } \\
\text { (Lon. } \times \text { Lat.) }\end{array}$ & Institute \\
\hline GFDL-ESM2M & $720 \times 360$ & $\begin{array}{l}\text { NOAA/Geophysical Fluid } \\
\text { Dynamics Laboratory }\end{array}$ \\
\hline HadGEM2-ES & $720 \times 360$ & Met Office Hadley Center \\
\hline IPSL-CM5A-LR & $720 \times 360$ & L'Institute Pierre-Simon Laplace \\
\hline MIROC-ESM-CHEM & $720 \times 360$ & AORI, NIES, and JAMSTEC \\
\hline NoerESM1-M & $720 \times 360$ & Norwegian Climate Center \\
\hline
\end{tabular}

The output of each GCM was bias corrected and downscaled to the $0.5^{\circ} \times 0.5^{\circ}$ spatial resolution

(Table 1). We verified these data sets against historical data in our previous study, and showed that the ISI-MIP data could largely reflect the real climatic conditions of the JRB [11]. With this, the future climate forcing data was used to drive the SWAT-DayCent model to predict the hydro-biogeochemical processes for the rest of the twenty-first century.

\section{Analysis of responses of SOC loss to climate warming and SWC}

In many previous studies, the SOC loss or decomposition rate had always been found to have a quadratic or exponential relationship with warming or SWC or their interaction $[21,27,35,50]$. Driven by this trend, we used the Gauss-Newton algorithm to establish the quadratic relationships (model) between the SOC loss and warming or SWC or their interaction. Following previous studies [51-54], we mainly concentrated on the root-zone SWC (i.e., SWC below $10 \mathrm{~cm}$ but above $300 \mathrm{~cm}$ of the soil depth [55]) and the top 90-cm SOC of the soil profile. There are several reasons why we chose the root-zone SWC and $90-\mathrm{cm} \mathrm{SOC}$ in this study. On the one hand, the root-zone SWC plays a vital role in the water-limited Loess Plateau, which is characterized by a thick vadose zone and deep groundwater level, because it is explicitly linked with the vegetation growth and carbon allocation into above- and below-ground biomass [56, 57]. For example, Gao et al. [58] investigated the afforestation effects on deep root-zone SWC $(2-8 \mathrm{~m})$ and shallowlayer SOC $(0-1.6 \mathrm{~m})$ and their relationships; Feng et al. [59] found there existed significant correlations between root-zone SWC and shallow-layer SOC $(<2 \mathrm{~m})$ by comparing relationships among different soil depths in the Loess Plateau region. On the other hand, global quantification had revealed that $\sim 55 \%$ of the top $1-\mathrm{m}$ SOC lied below $0.3-\mathrm{m}$ depth and, thus, a top $90-\mathrm{cm}$ SOC could more reasonably represent the SOC content of a specific ecosystem than other depths (e.g., the widely-used 20-cm SOC) [2]. This is especially the case in the Loess Plateau, 
which has a thick loess deposit with a significant decrease of SOC level along depth. The nonlinear statistical model proposed in this study were:

$$
\begin{aligned}
& \Delta C_{t}=a \Delta T^{2} \\
& \Delta C_{s w c}=\mathrm{b} \Delta S W C^{2}+c \Delta S W C \\
& \Delta C_{(t+s w c)}=\mathrm{d} \Delta T^{2}+\mathrm{e} \Delta S W C^{2}+f \Delta S W C
\end{aligned}
$$

where $\Delta C_{t}, \Delta C_{s w c}$ and $\Delta C_{(t+s w c)}$ are the SOC changes caused by warming, SWC change, and their interaction, respectively; $\Delta T$ indicates the warming level $\left({ }^{\circ} \mathrm{C}\right.$ ) (the air temperature difference between the future conditions and the baseline (1976-2016); $\triangle S W C$ indicates the change of SWC $(\mathrm{mm})$ (i.e., the average soil water content during the future climate minus the average ones during the historical period (1976-2016)); and a, b, c, d, e, and f represent the fitted coefficients for the statistical models.

We performed model selection in terms of the Akaike information criterion (AIC) and Bayesian information criterion (BIC). A lower AIC or BIC indicates a better fit. Based on the final fitted nonlinear models, we investigated the responses of the SOC loss to climate warming and SWC change under the three RCPs. The impacts of climate change on SOC and SWC were investigated by comparing the differences between the baseline conditions (1976-2016) and future projections (2017-2099) from the model outputs. Besides, we used the nonparametric deviance reduction analysis as an auxiliary [60] to detect the change-point of an ecological indicator along another one. This method estimates the numerical value of a predictor $x$, resulting an abrupt change in the response variable, $y$, represented as the cumulative probability of a change-point [61]. Before and after this change-point, the relationship between two environmental indicators (for example, the SWC change and SOC loss in our study) may be different, and thus this point can approximately be the threshold in regulating the responses.

\section{Results}

Temporal changes in historical and future climate, SWC, and SOC

The historical and projected changes in climate (air temperature and precipitation), SWC, and SOC under RCP2.6, RCP4.5, and RCP8.5 are shown in Fig. 2. The average air temperature had been increasing during the historical period (1976-2016) and was projected to continuously increase during the future period (2017-2099) under all RCPs, indicating a significant warming trend for the twenty-first century in the JRB. Specifically, the annual mean temperature increased by $1.8^{\circ} \mathrm{C}$ from 1976
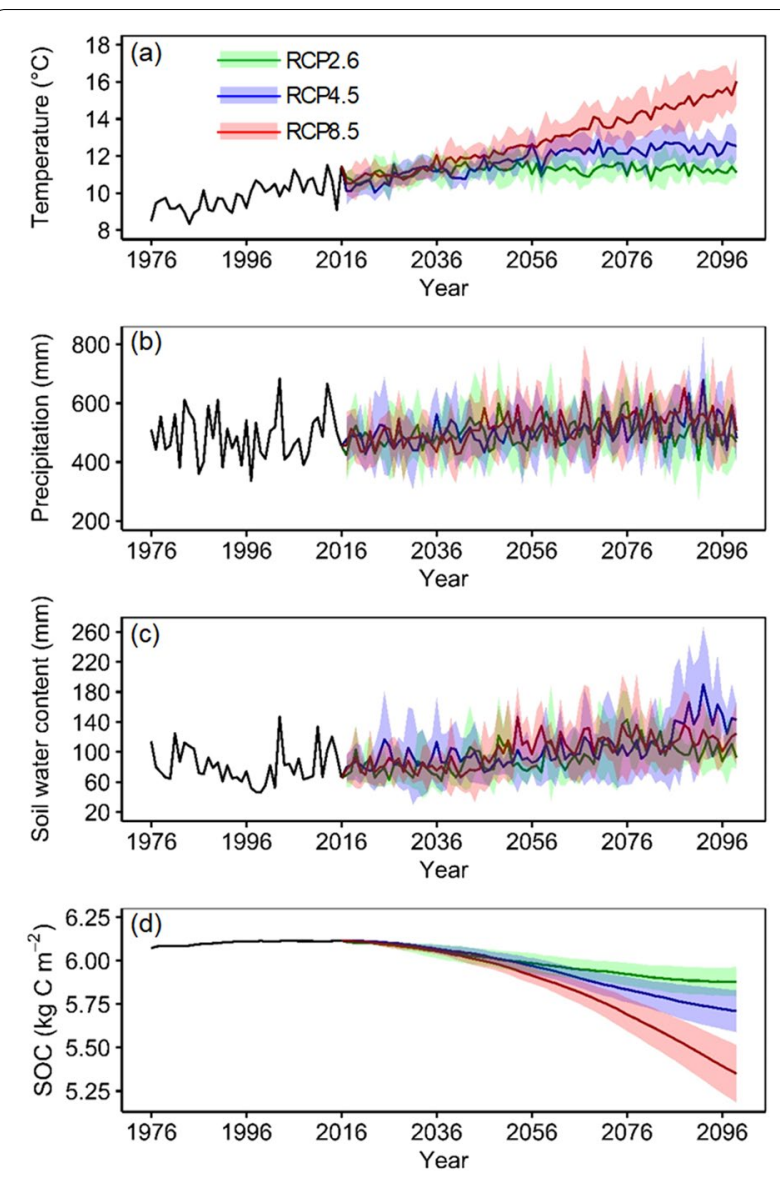

Fig. 2 Projected changes in a average air temperature, $\mathbf{b}$ precipitation, $\mathbf{c}$ soil water content (root zone), and $\mathbf{d}$ SOC. The shading area (uncertainty range) denotes the \pm 1 standard deviation range of model annual averages

to 2016, with a rate of $0.46{ }^{\circ} \mathrm{C}$ per decade. Although the warming rate would become lower under RCP2.6 $\left(0.02{ }^{\circ} \mathrm{C}\right.$ per decade) and RCP4.5 $\left(0.28{ }^{\circ} \mathrm{C}\right.$ per decade) from 2017 to 2099 , it would reach $0.63^{\circ} \mathrm{C}$ per decade under RCP8.5, i.e., $18 \%$ of increase compared to the historical period. The annual precipitation showed an upward trend during the historical period ( $4.2 \mathrm{~mm}$ per decade) and was also projected to increase with a rate of $3.8,7.7$, and $12.0 \mathrm{~mm}$ per decade during the future period (2017-2099) under RCP2.6, RCP4.5, and RCP8.5, respectively, indicating a wetting trend in the JRB. Compared to the historical condition, the average air temperature and precipitation during the prediction period would increase by $1.4,1.9$, and $3.1{ }^{\circ} \mathrm{C}$ and $2.0 \%, 13.1 \%$, and $6.0 \%$ under RCP2.6, 4.5, and 8.5 , respectively (Table 2 ).

It was projected that the changes in annual SWC were relatively consistent with the changes in annual precipitation across all climate scenarios (Fig. 2c). The SWC showed a periodic fluctuation during the historical 
Table 2 Projected future (2017-2099) changes in climate (temperature $(\triangle \mathrm{T})$ and precipitation $(\triangle \mathrm{P})$ ) and SWC ( $\triangle \mathrm{SWC}$ ) and soil organic carbon $(\triangle S O C)$ relative to the historical period (19762016)

\begin{tabular}{llcll}
\hline Scenario & $\boldsymbol{\Delta} \mathbf{T}\left({ }^{\circ} \mathrm{C}\right)$ & $\boldsymbol{\Delta P}(\%)$ & $\boldsymbol{\Delta S W C}(\%)$ & $\begin{array}{l}\boldsymbol{\Delta} \mathbf{S O C}(\mathbf{k g ~ C} \\
\left.\mathbf{m}^{-\mathbf{2}} \mathbf{y e a r}^{-1}\right)\end{array}$ \\
\hline RCP2.6 & 1.4 & 2.0 & 14.1 & -0.12 \\
RCP4.5 & 1.9 & 13.1 & 27.9 & -0.16 \\
RCP8.5 & 3.1 & 6.0 & 25.4 & -0.26 \\
\hline
\end{tabular}

period (1976-2016), while it showed an upward trend during the future period (2017-2099). In comparison with the historical period, the basin-scale annual average SWC would increase by $14.1 \%, 27.9 \%$, and $25.4 \%$ under RCP2.6, RCP4.5, and RCP8.5 by the end of the twentyfirst century (Table 2). As can be seen from Fig. 2d, although the SOC increased slightly from 1976-2016, it would decrease across all climate scenarios with the highest depletion rate occurring in RCP8.5 $(-0.09 \mathrm{~kg} \mathrm{C}$ $\mathrm{m}^{-2}$ per decade). As shown in Table 2, when compared to the historical condition, the SOC would decrease by 0.12 , 0.16 , and $0.26 \mathrm{~kg} \mathrm{C} \mathrm{m}^{-2}$ year $^{-1}$ under RCP2.6, RCP4.5, and RCP8.5, respectively, indicating a potential carbon source under climate warming in the JRB.

\section{Spatial patterns of SWC and SOC changes under future climate}

Figure 3 shows the spatial patterns of SWC (the upper panel) and SOC (the lower panel) and their changes under RCP2.6, RCP4.5, and RCP8.5. During the historical period, the lower and higher SWC were primarily located in the northern and southern areas, respectively. The annual average SWC showed an increasing gradient from the north to the south with a range of $10 \mathrm{~mm}$ to $450 \mathrm{~mm}$ (as shown in the side bars) during 1976-2016. Some portions in southern areas and northern margins showed

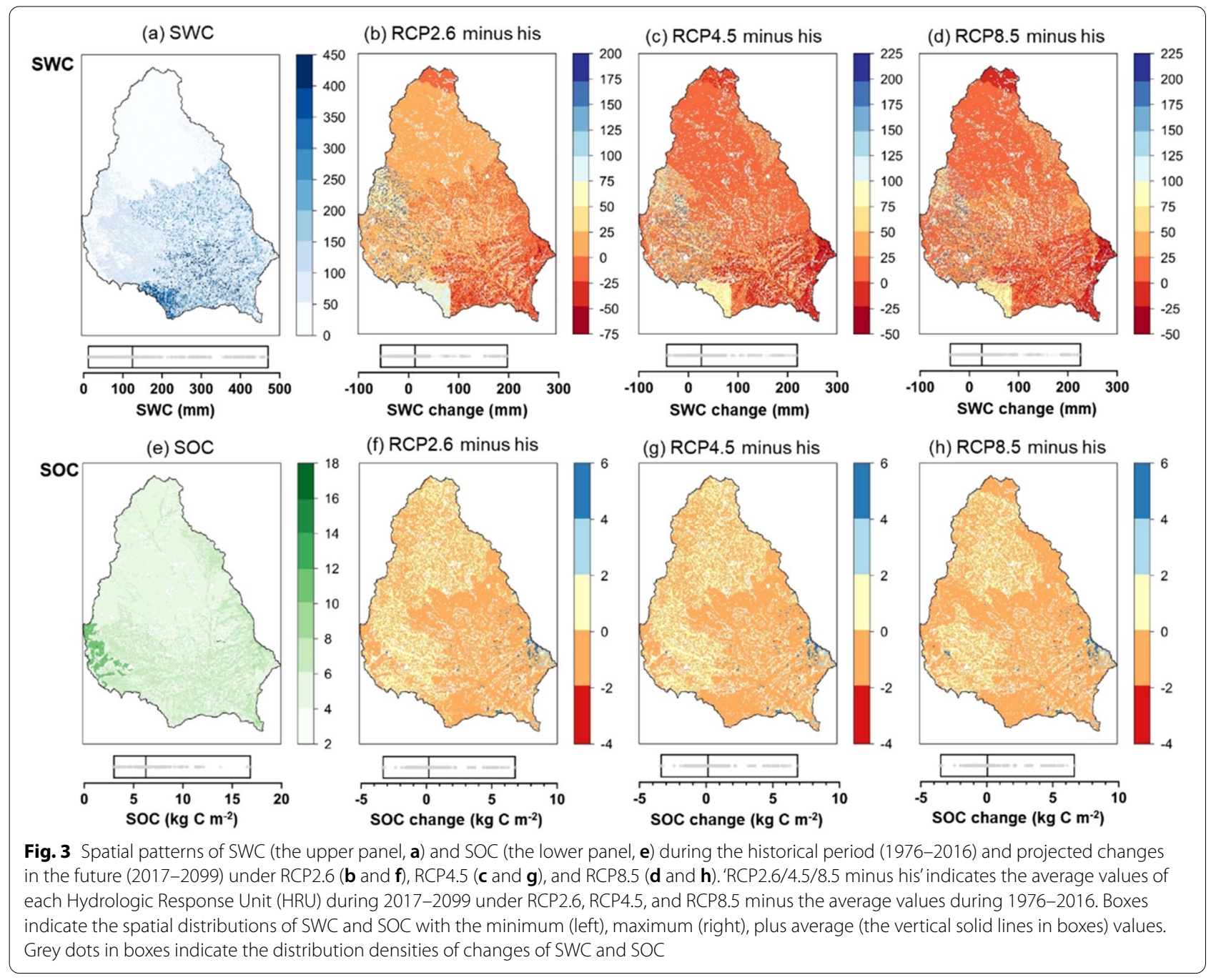


relatively larger decreased magnitudes, while other areas were projected to increase with increased magnitude ranging from 0 to $225 \mathrm{~mm}$. For SOC, the basin average SOC density was $6.2 \mathrm{~kg} \mathrm{C} \mathrm{m}^{-2}$, with higher values in the western margin (Fig. 3). The SOC in most parts of the southern basin were projected to decrease with a decreasing magnitude ranging from -4 to $0 \mathrm{~kg} \mathrm{C} \mathrm{m}^{-2}$ across the three RCPs (as shown in the side bars). Large areas in the north basin and small portions in the southeastern margin showed an increase in SOC, indicating a potential carbon sink in these areas under the future climate conditions.

\section{Nonlinear responses of SOC loss to warming and soil water variation}

As stated in "Temporal changes in historical and future climate, SWC, and SOC", SOC was projected to decrease in the future but the decreasing magnitude varied among different climate scenarios. To investigate the nonlinear responses of the projected SOC loss to climate warming and SWC, we used the Gauss-Newton algorithm to establish the nonlinear relationships between the SOC loss and warming (Eq. 1) or SWC (Eq. 2) or their interaction (Eq. 3). When plotting the projected root-zone SWC change against the SOC loss based on Eq. 1 (as shown in Fig. 4), the SWC change and the SOC loss had a significant $(P<0.05)$ quadratic relationship with the correlation coefficients (r) ranging from 0.67 to 0.77 . The comparison showed that both the AIC and BIC values in models between the SOC loss and warming or SWC change individually were higher than those between the SOC loss and the interactions between warming and SWC change (as shown in Tables 3 and 4). This phenomenon demonstrated that the best-fit response model should include both warming and SWC change, which could more reasonably explain the SOC loss under future climate
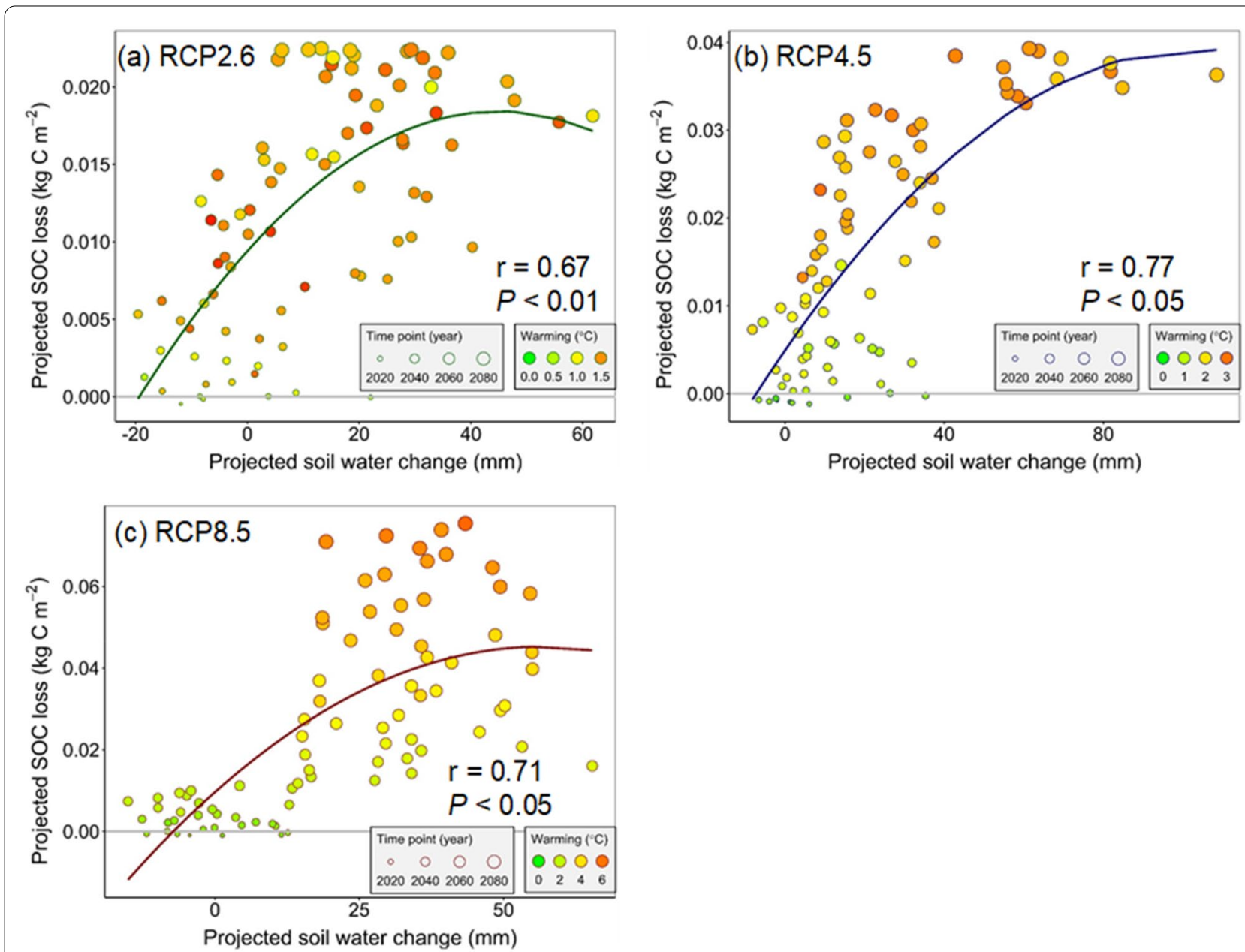

Fig. 4 Relationships between changes in SWC and SOC loss under RCP2.6, RCP4.5, and RCP8.5. Bubble size indicates the time point during 2017-2099, and the color shows different warming levels (the air temperature difference between the baseline condition (1976-2016) and future climate conditions (2017-2099)) 
Table 3 Fitted nonlinear models between SOC loss and climate warming and SWC change

\begin{tabular}{|c|c|c|c|}
\hline Scenario & Model & AIC & BIC \\
\hline RCP2.6 & $\begin{array}{l}\Delta C_{(t+s w c)}=0.002 \Delta T^{2}- \\
0.000002 \Delta S W C^{2}+0.0001 \Delta S W C\end{array}$ & -611 & -602 \\
\hline RCP4.5 & $\begin{array}{l}\Delta C_{(t+\text { swc })}=0.003 \Delta T^{2}+0.0000005 \Delta S W C^{2} \\
\quad+0.0002 \Delta S W C\end{array}$ & -646 & -636 \\
\hline RCP8.5 & $\begin{array}{l}\Delta C_{(t+\text { swc })}=0.004 \Delta T^{2}- \\
0.000003 \Delta S W C^{2}+0.0003 \Delta S W C\end{array}$ & -712 & -702 \\
\hline
\end{tabular}

AIC: Akaike Information Criterion; BIC: Bayesian Information Criterion

Table 4 AIC and BIC for the fitted nonlinear models between the SOC loss and warming or SWC

\begin{tabular}{llll}
\hline & RCPs & AIC & BIC \\
\hline SOC loss versus warming alone (quadratic) & RCP2.6 & -575 & -571 \\
& RCP4.5 & -594 & -589 \\
& RCP8.5 & -704 & -699 \\
SOC loss versus SWC alone (quadratic) & RCP2.6 & -530 & -523 \\
& RCP4.5 & -541 & -534 \\
& RCP8.5 & -429 & -427 \\
SOC loss versus warming and SWC (expo- & RCP2.6 & -529 & -520 \\
nential combined with quadratic) & RCP4.5 & -574 & -565 \\
& RCP8.5 & -569 & -559 \\
\hline
\end{tabular}

AIC: Akaike Information Criterion; BIC: Bayesian Information Criterion

conditions. To validate the fitted nonlinear models, we compared the modeling results with those simulated by SWAT-DayCent (Additional file 1: Figure S1). The comparison showed that the best-fit nonlinear model (Eq. 3) could accurately discern the SOC loss across all climate scenarios ( $\mathrm{r}$ were $0.66,0.94$, and 0.99 under RCP2.6, RCP4.5, and RCP8.5, respectively, $P<0.001$ ), and thus we used these nonlinear response models to explain the SOC loss in the JRB.

Based on the final fitted nonlinear model, we generated the response surfaces (Fig. 5). As shown in Fig. 5, the hump-shaped response surfaces were found in both RCP2.6 and RCP8.5, whereas this was not evident in the RCP4.5. A clear ridge (i.e., the threshold of changing SWC) was observed under both RCP2.6 and RCP8.5 (Fig. 4). The changing threshold of SWC was 25 and $50 \mathrm{~mm}$ under RCP2.6 and RCP8.5, respectively. Under both RCP2.6 and RCP8.5, when the changes in SWC were lower than the thresholds, warming would accelerate the SOC loss from soil, whereas the soil water could alleviate the warming-induced SOC loss when it was higher than this threshold. This phenomenon demonstrated the key role of SWC in affecting the SOC loss under a warming climate. However, this water mediation of warming effects was not detected in RCP4.5, where the SOC loss increased following the warming and SWC gradient (Fig. 5b). It was found that the SOC loss increased with increasing SWC but kept relatively stable after reaching a certain level (a quadratic relationship with a downward opening) (Fig. 4b), where the SOC loss was almost unchanged across gradients of warming and SWC. To explain this phenomenon, we used nonparametric deviance reduction analysis to detect the SWC change-point along SOC loss and found that the relationship change occurred at $41 \mathrm{~mm}$ of projected SWC change (Fig. 4b), indicating that the SWC could still mediate the response of SOC loss to warming across the full range of warming under RCP4.5 when considering SWC alone. However, this water mediation diminished when interacting with climate warming and the combined effects of SWC and warming on SOC loss would change to be positive.

\section{Discussion \\ SOC loss caused by warming}

Predicting the spatiotemporal changes in SOC is of great importance, as it is explicitly linked with the soil functions and many ecosystem services. Our study predicted that SOC during the future period would become significantly lower across all climate scenarios. This phenomenon demonstrated a potential carbon source of the JRB in the twenty-first century, which has also been confirmed by previous studies $[11,62,63]$. The significant SOC depletion can be attributed to the warmer climate in the future, despite the increased SWC induced by an increased precipitation (Fig. 6) [23, 64]. The warming effects on the SOC depletion can be explained by several candidate mechanisms. On the one hand, elevated air temperature can induce an increase in soil temperature, which would activate the microbial activities and accelerate the SOC decomposition rate [65]. On the other hand, both the meta-analysis and experimental results, from past studies, have indicated that the plant photosynthesis is more sensitive to the warming/drought than respiration [31, 66, 67]. A global-scale study has also revealed that a warmer year (less water availability) was always associated with faster $\mathrm{CO}_{2}$ growth, demonstrating the critical role of warming in the SOC decomposition [68]. Some quantitative studies have also assessed the response of SOC to climate warming, which were in line with our study [69]. For example, an expected increase in air temperature of $3.3^{\circ} \mathrm{C}$ would cause an SOC loss of $11-16 \%$ over the Europe, and an average increase in surface air temperature of $1{ }^{\circ} \mathrm{C}$ would cause a net loss of $5 \%$ of the SOC pool globally. In brief, our analysis demonstrated that anthropogenic-induced future climate warming alone would always result in SOC loss across the full range of SWC. 
(a) RCP2.6
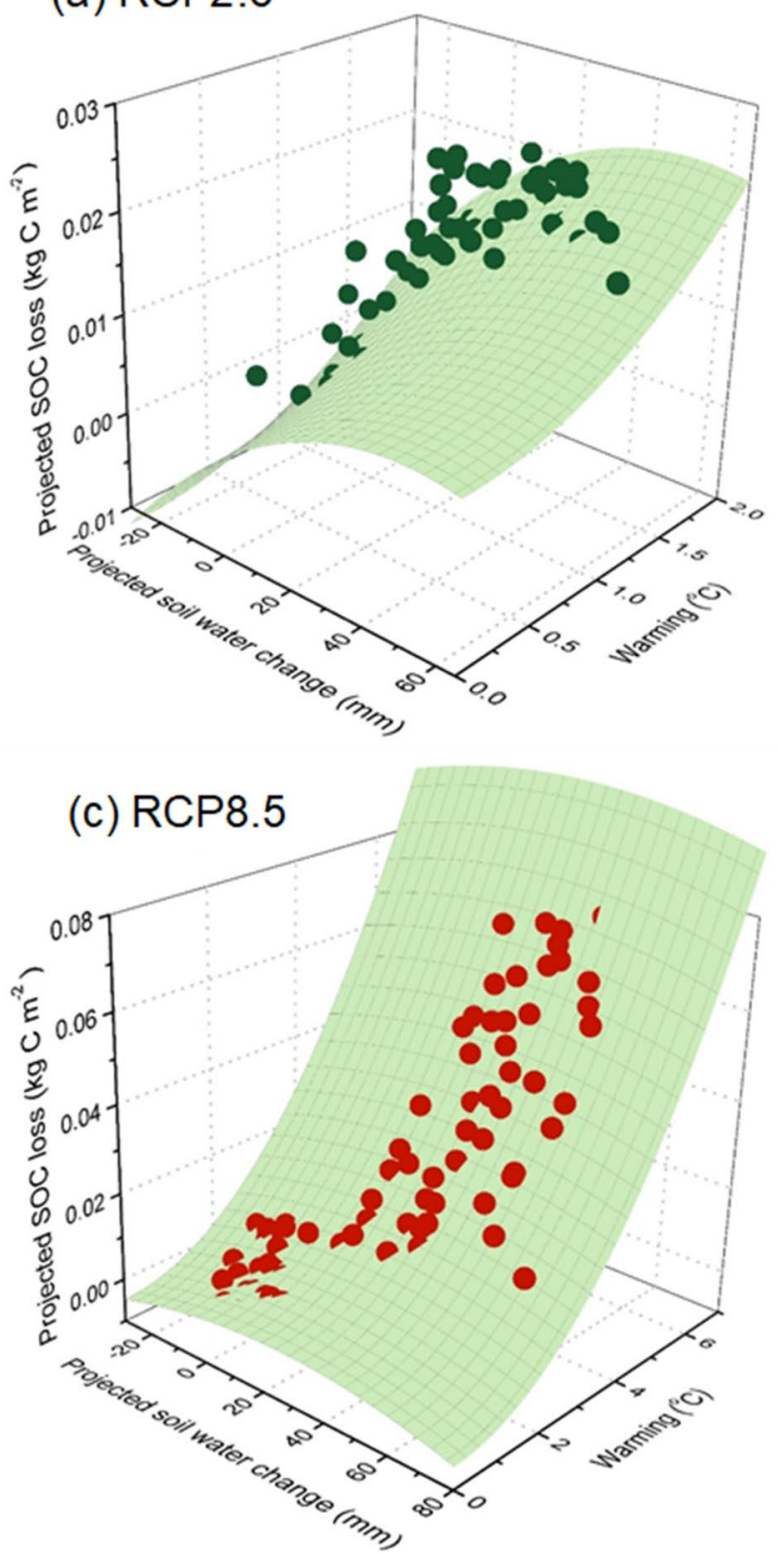

\section{(b) RCP4.5}

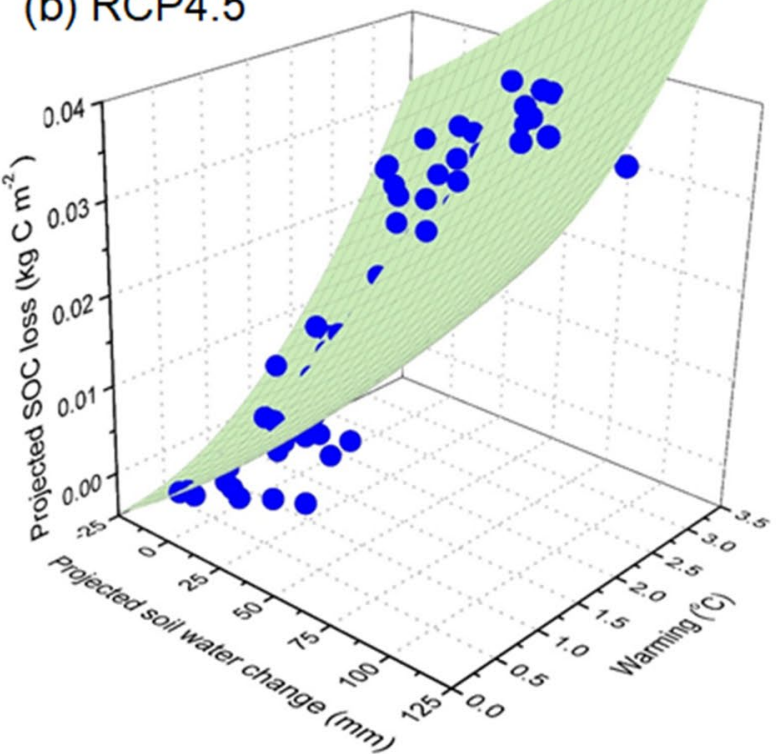

Fig. 5 Response surfaces of the relationships between root-zone SWC and climate warming and SOC loss under RCP2.6, RCP4.5, and RCP8.5. Observed values (the green, blue, and red dots) are the means of projected SOC loss from five GCMs, and the modeled values (the green surfaces) are predictions from the fitted nonlinear models

\section{Water-mediated warming effects on SOC}

Soil water content (water availability) plays a crucial role in determining the response of the SOC loss to climate warming through affecting the soil respiration and plant productivity directly [70-72]. Many previous experimental studies have revealed a quadratic relationship between the soil water content and soil respiration (SOC loss), which were in line with our findings in the JRB. 

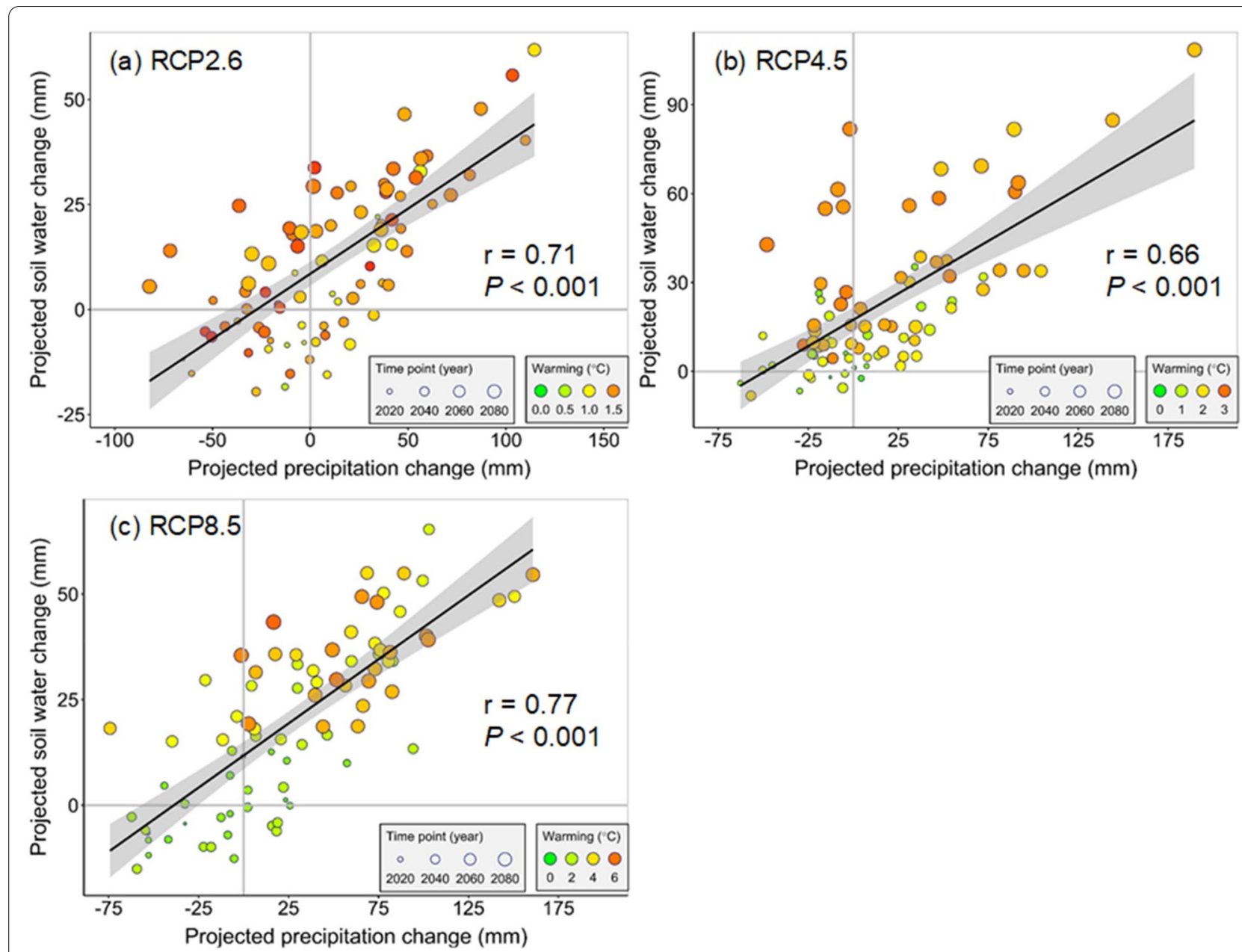

Fig. 6 Relationships between changes in precipitation and SWC under a RCP2.6, b RCP4.5, and c RCP8.5. Bubble size indicates the time point during 2017-2099, and the color shows different warming levels

For example, Jassal et al. [70] found that there existed a quadratic relationship between the basal respiration and SWC in an old temperature Douglas-fir stand. In a constructed old-field grassland, Wan et al. [36] also reported a second-order polynomial function between SWC and soil respiration. These studies support our findings that the SWC would exert different effects on SOC under different contents-a quadratic relationship between the predicted SOC loss and SWC (Fig. 4). When plotting the combined effects of warming and SWC change against the predicted SOC loss, we found hump-shape response surfaces under RCP2.6 and RCP8.5, which implied that the warming effects on SOC (warming-induce SOC loss) were meditated by the SWC changes. Under the warming climate in both RCP2.6 and RCP8.5, the SWC would stimulate the SOC loss when its change was below the threshold (the ridge of the hump-shaped surface) (a drier or slightly wetter trend compared to the baseline condition), while the increased root-zone SWC would alleviate the warming-induced SOC loss when its positive change was above the threshold (a relatively large wetter condition) (Fig. 5). The threshold became higher under RCP8.5 (high warming level) than that under RCP2.6 (low warming level). In general, under adequate water availability, warming can consistently promote plant growth and enhance $C$ sequestration $[27,73]$, while the warminginduced droughts can also limit both $\mathrm{C}$ uptake and soil respiration under the water deficit conditions [74, 75]. These two mechanisms might be the reasons that the magnitude of SOC loss increased first and then decreased with increasing the SWC under the warming climate in our estimated response surfaces. The findings highlighted that the positive effects of warming on SOC loss could be partly mediated by SWC, which may lead to variable C-climate feedbacks under different SWC conditions in the JRB. Our findings may also have implications for the managements of terrestrial ecosystems under the future warmer climate. Ecosystems in dry regions (lower SWC) 
most likely act as carbon sources under future warmer climate conditions and thus cause a positive feedback to climate warming, while ecosystems in wet regions (higher SWC) possibly generate a negative feedback. The policy makers should seek different management measures in ecosystems with different SWC under the future warmer climate. Actually, this mechanism derived in our study was generally supported by the global-scale study that warming stimulates carbon release in low-precipitation regions but enhances the carbon uptake in high-precipitation areas [27]. Thus, some studies held that there existed a threshold of precipitation that regulated the net carbon exchange at continental scales [34].

It was worth noting that this water mediation was not found in RCP4.5, which might be attributed to the higher inter-annual variability (IAV) of SWC in RCP4.5 compared to that in RCP2.6 and RCP8.5 (Additional file 1: Figure S2) and the IAV-induced inconsistent change of SOC loss (Additional file 1: Figure S3). A higher IAV (less stable) of SWC in this water-limited loess watershed would exert a persistent stimulation for the microbial activities, leading to continuous decomposition of SOC under the climate warming [76, 77]. According to the research implemented in semiarid steppes by Rey et al. [76], a sudden change in soil moisture caused by higher IAV of precipitation would contribute to about $65 \sim 80 \%$ of total carbon losses at different vegetation covers. An experimental study conducted in the Loess Plateau, which is similar to our study area, has proved that the higher variability of SWC caused by pulsed rainfall could significantly stimulate the $C$ loss from soil and explain a large portion of the variation in soil respiration (above 50\%) [78]. Thus, the combined warming and SWC change and IAV contributed to a persistent SOC loss in the JRB, which raised a caution to consider the variability of water availability (including both precipitation and SWC) when investigating the C-climate feedbacks.

\section{Limitations and uncertainties}

In our study, we used the quadratic functions to analyze the relationships between the SOC loss and warming or SWC or their interaction, which may simplify the mechanism of the responses of the $\mathrm{C}$ cycle to warming and hydrological cycle. In fact, many previous experimental studies have used a variety of response functions, such as linear [12], quadratic [31, 79], and exponential [80], to depict the carbon cycle responses to warming and SWC. For example, Quan et al. [27] combined a quadratic function between NEP (net ecosystem productivity) and SWC and an exponential function between carbon cycles and climate warming to generate a continuous model to discern the water scaling pattern of warming effects on the carbon cycle. In the present study, we also tried the exponential function between climate warming and the SOC loss by reproducing their approach [27] but achieved only poor performance (Table 4). This phenomenon demonstrated that the quadratic model used in our study was more reasonable to represent the $C$ response to climate warming and SWC change in the JRB.

Uncertainties involved in this study can be primarily attributed to the GCMs and the hydrological modeling approach. Considering the sophisticated climate system and the potential uncertainties of the GCM outputs, we used an ensemble of five GCMs to drive the hydro-biogeochemical model and could observe a certain level of uncertainties in the predicted water and carbon components (see the uncertainty bands in Fig. 2). Though the model verification showed that SWAT-DayCent could accurately simulate the water and carbon cycles in the JRB, it was inevitable that bias would occur due to the multiple influencing factors of remotely-sensed NPP, such as meteorological conditions (clouds and aerosols), vegetation conditions, and sensors. In addition, we assumed that the land use information was constant in the simulations, which might have led to an overestimation or underestimation of the water and carbon components. We will consider the dynamic land use information in the simulations using SWAT-DayCent and other process-based models in future studies. It is worth noting that we only investigated SOC change and its responses to climate warming and SWC change in this study and did not consider other driving factors (e.g., the plant/ animal litter input, the soil respiration loss, and nutrient stimulation). We noted these factors may play important roles in driving SOC changes in the JRB during our study period, leading to uncertainties in the analysis. Future studies could consider more factors in driving SOC change to gain a more comprehensive understanding of how carbon cycle responses to the climate change under a more complex environment.

\section{Conclusions}

In this study, we quantitatively investigated the spatiotemporal changes in soil organic carbon (SOC) and its responses to both climate warming and soil water content (SWC) in the Jinghe River Basin (JRB) in China, by combining the Global Circulation Model (GCM) output and a coupled SWAT-DayCent model. The future climate projections showed that the air temperature would increase significantly across all the three scenarios considered (RCP2.6, RCP4.5, and RCP8.5), and the precipitation would increase by $2.0-13.1 \%$ by the end of the twenty-first century, indicating a warmer and wetter climate during the twenty-first century in the JRB. The SWC was projected to increase by $14.1-27.9 \%$ owing to the increased precipitation, while the SOC 
would significantly decrease during the future period, with varying degrees among the different climate scenarios. Through analyzing the relationships between the projected SOC loss and climate warming, SWC change, and their interaction, we showed that there existed a changing SWC threshold which could mediate the warming-induced SOC loss. When the SWC change was lower than the threshold, a higher SWC would accelerate the SOC loss; when the SWC change was higher than the threshold, a higher SWC would depress the SOC loss. This water mediation pattern would help the watershed managers make effective and efficient policies and measures to enhance the $C$ sequestration in a warming climate.

\section{Abbreviations}

JRB: Jinghe River Basin; SWAT: Soil and Water Assessment Tool; SOC: Soil Organic Carbon; SWC: Soil Water Content; NPP: Net Primary Productivity; ET: Evapotranspiration; GCM: Global Climate Model; RCP: Representative Concentration Pathway; ISI-MIP: Inter-Sectoral Impact Model Inter-comparison Project; CMIP5: Coupled Model Inter-comparison Project Phase 5; DEM: Digital Elevation Model; CRU: Climatic Research Unit; SRTM: Shuttle Radar Topography Mission; CMA: China Meteorological Administration; AIC: Akaike Information Criterion; BIC: Bayesian Information Criterion; NSE: Nash-Sutcliffe Efficiency.

\section{Supplementary Information}

The online version contains supplementary material available at https://doi. org/10.1186/s13021-021-00187-2.

Additional file 1. Additional figures.

\section{Acknowledgements}

We thank the HPCC Platform in Xi'an Jiaotong University for computing equipment and computer maintenance. We thank the editor and the anonymous reviewers for the constructive comments and suggestions.

\section{Authors' contributions}

FBZ and YPW conceived and designed the study. FBZ conducted the analyses. All authors reviewed and edited the manuscript. All authors read and approved the final manuscript.

\section{Funding}

This study was funded by the National Science Foundation of China (31961143011), the China Postdoctoral Science Foundation (2020M683451), the Strategic Priority Research Program of the Chinese Academy of Sciences (XDB40020205), the Shaanxi Major Theoretical and Practical Program (20ST106), the Innovation Team of Shaanxi Province (2021TD-52), and the National Thousand Youth Talent Program of China.

\section{Availability of data and materials}

The data and materials are available upon reasonable request.

\section{Declarations}

\section{Competing interests}

The authors declare that they have no competing interests.

\section{Author details}

'Department of Earth \& Environmental Science, School of Human Settlements and Civil Engineering, Xi'an Jiaotong University, Xi'an 710049, Shaanxi, China. ${ }^{2}$ Department of Civil Engineering, Indian Institute of Technology
Bombay, Powai, Mumbai, Maharashtra 400076, India. ${ }^{3}$ College of Resources and Environmental Sciences, China Agricultural University, Beijing 100094, China. ${ }^{4}$ National Engineering Laboratory for Applied Technology of Forestry and Ecology in South China, Central South University of Forestry and Technology, Changsha 410004, China.

Received: 28 December 2020 Accepted: 7 August 2021

Published online: 16 August 2021

\section{References}

1. Dlamini P, Chivenge P, Chaplot V. Overgrazing decreases soil organic carbon stocks the most under dry climates and low soil pH: a meta-analysis shows. Agr Ecosyst Environ. 2016;221:258-69.

2. Lal R. Digging deeper: a holistic perspective of factors affecting soil organic carbon sequestration in agroecosystems. Glob Chang Biol. 2018;24(8):3285-301.

3. Zhang K, Dang H, Zhang Q, Cheng X. Soil carbon dynamics following land-use change varied with temperature and precipitation gradients: evidence from stable isotopes. Glob Chang Biol. 2015;21(7):2762-72.

4. Piao S, Wang X, Wang K, Li X, Bastos A, Canadell JG, et al. Interannual variation of terrestrial carbon cycle: Issues and perspectives. Glob Chang Biol. 2019:26(1):300-18.

5. Wu Y, Liu S, Tan Z. Quantitative attribution of major driving forces on soil organic carbon dynamics. J Adv Model Earth Syst. 2015;7(1):21-34.

6. Lal R. Soil carbon sequestration impacts on global climate change and food security. Science. 2004;304(5677):1623-7.

7. Crowther TW, Todd-Brown KE, Rowe CW, Wieder WR, Carey JC, Machmuller MB, et al. Quantifying global soil carbon losses in response to warming. Nature. 2016:540(7631):104-8.

8. Balesdent J, Basile-Doelsch I, Chadoeuf J, Cornu S, Derrien D, Fekiacova Z, et al. Atmosphere-soil carbon transfer as a function of soil depth. Nature. 2018;559(7715):599-602.

9. Sato A, Nojiri Y. Assessing the contribution of harvested wood products under greenhouse gas estimation: accounting under the Paris Agreement and the potential for double-counting among the choice of approaches. Carbon Balance Manag. 2019;14(1):15.

10. Wu Y, Zhao F, Liu S, Wang L, Qiu L, Alexandrov G, et al. Bioenergy production and environmental impacts. Geosci Lett. 2018;5(1):1-9.

11. Zhao F, Wu Y, Yao Y, Sun $K$, Zhang $X$, Winowiecki L, et al. Predicting the climate change impacts on water-carbon coupling cycles for a loess hillygully watershed. J Hydrol. 2020;581:124388.

12. Zhao F, Wu Y, Sivakumar B, Long A, Qiu L, Chen J, et al. Climatic and hydrologic controls on net primary production in a semiarid loess watershed. J Hydrol. 2019;568:803-15.

13. Ren W, Banger K, Tao B, Yang J, Huang Y, Tian H. Global pattern and change of cropland soil organic carbon during 1901-2010: roles of climate, atmospheric chemistry, land use and management. Geogr Sustain. 2020;1 (1):59-69.

14. Zhao F, Wu Y, Qiu L, Bellie S, Zhang F, Sun Y, et al. Spatiotemporal features of the hydro-biogeochemical cycles in a typical loess gully watershed. Ecol Ind. 2018:91:542-54

15. Reyna-Bowen L, Fernandez-Rebollo P, Fernández-Habas J, Gómez JA. The influence of tree and soil management on soil organic carbon stock and pools in dehesa systems. Catena. 2020;190:104511.

16. Calvo de Anta R, Luís E, Febrero-Bande M, Galiñanes J, Macías F, Ortíz R, et al. Soil organic carbon in peninsular Spain: influence of environmental factors and spatial distribution. Geoderma. 2020;370:114365.

17. Guan S, An N, Zong N, He Y, Shi P, Zhang J, et al. Climate warming impacts on soil organic carbon fractions and aggregate stability in a Tibetan alpine meadow. Soil Biol Biochem. 2018;116:224-36.

18. Zatta A, Clifton-Brown J, Robson P, Hastings A, Monti A. Land use change from C3 grassland to C4Miscanthus: effects on soil carbon content and estimated mitigation benefit after six years. GCB Bioenergy. 2014;6(4):360-70.

19. Qin Z, Huang Y, Zhuang Q. Soil organic carbon sequestration potential of cropland in China. Global Biogeochem Cycles. 2013;27(3):711-22.

20. England JR, Paul KI, Cunningham SC, Madhavan DB, Baker TG, Read Z, et al. Previous land use and climate influence differences in soil organic 
carbon following reforestation of agricultural land with mixed-species plantings. Agr Ecosyst Environ. 2016;227:61-72.

21. Conant RT, Ryan MG, Ågren Gl, Birge HE, Davidson EA, Eliasson PE, et al. Temperature and soil organic matter decomposition rates synthesis of current knowledge and a way forward. Glob Change Biol. 2011;17(11):3392-404.

22. Kirschbaum M. The temperature dependence of organic-matter decomposition —still a topic of debate. Soil Biol Biochem. 2006;38(9):2510-8.

23. Arora VK, Boer GJ, Friedlingstein P, Eby M, Jones CD, Christian JR, et al. Carbon-concentration and carbon-climate feedbacks in CMIP5 earth system models. J Clim. 2013;26(15):5289-314.

24. Ahlstrom A, Raupach MR, Schurgers G, Smith B, Arneth A, Jung M, et al. The dominant role of semi-arid ecosystems in the trend and variability of the land CO(2) sink. Science. 2015;348(6237):895-9.

25. Piao S, Ciais P, Friedlingstein P, Peylin P, Reichstein M, Luyssaert S, et al. Net carbon dioxide losses of northern ecosystems in response to autumn warming. Nature. 2008;451(7174):49-52.

26. Hakkenberg R, Churkina G, Rodeghiero M, Börner A, Steinhof A, Cescattl A. Temperature sensitivity of the turnover times of soil organic matter in forests. Ecol Appl. 2008;18(1):119-31.

27. Quan Q, Tian D, Luo Y, Zhang F. Water scaling of ecosystem carbon cycle feedback to climate warming. Sci Adv. 2019;5:1131.

28. Zhang Z, Zhang R, Cescatti A, Wohlfahrt G, Buchmann N, Zhu J, et al. Effect of climate warming on the annual terrestrial net ecosystem $\mathrm{CO} 2$ exchange globally in the boreal and temperate regions. Sci Rep. 2017;7(1):3108.

29. Giardina CP, Ryan MG. Evidence that decomposition rates of organic carbon in mineral soil do not vary with temperature. Nature. 2000:404(6780):858-61.

30. Schindlbacher A, Wunderlich S, Borken W, Kitzler B, ZechmeisterBoltenstern S, Jandl R. Soil respiration under climate change: prolonged summer drought offsets soil warming effects. Glob Change Biol. 2012;18(7):2270-9.

31. Niu S, Wu M, Han Y, Xia J, Li L, Wan S. Water-mediated responses of ecosystem carbon fluxes to climatic change in a temperate steppe. New Phytol. 2008;177(1):209-19.

32. Taylor PG, Cleveland CC, Wieder WR, Sullivan BW, Doughty CE, Dobrowski $\mathrm{SZ}$, et al. Temperature and rainfall interact to control carbon cycling in tropical forests. Ecol Lett. 2017;20(6):779-88.

33. Davidson EA, Janssens IA. Temperature sensitivity of soil carbon decomposition and feedbacks to climate change. Nature. 2006:440(7081):165-73.

34. Liu Z, Ballantyne AP, Poulter B, Anderegg WRL, Li W, Bastos A, et al. Precipitation thresholds regulate net carbon exchange at the continental scale. Nat Commun. 2018;9(1):3596

35. Jia B, Zhou G, Yuan W. Modeling and coupling of soil respiration and soil water content in fenced Leymus chinensis steppe, Inner Mongolia. Ecol Model. 2007;201(2):157-62.

36. Wan S, Norby RJ, Ledford J, Weltzin JF. Responses of soil respiration to elevated $\mathrm{CO} 2$, air warming, and changing soil water availability in a model old-field grassland. Glob Change Biol. 2007:13(11):2411-24.

37. Reich PB, Sendall KM, Stefanski A, Rich RL, Hobbie SE, Montgomery RA. Effects of climate warming on photosynthesis in boreal tree species depend on soil moisture. Nature. 2018;562(7726):263-7.

38. Zhao F, Wu Y, Qiu L, Sun Y, Sun L, Li Q, et al. Parameter uncertainty analysis of the SWAT model in a mountain-loess transitional watershed on the Chinese Loess Plateau. Water. 2018;10(6):690.

39. Zhang S, Wu Y, Sivakumar B, Mu X, Zhao F, Sun P, et al. Climate changeinduced drought evolution over the past 50 years in the southern Chinese Loess Plateau. Environ Model Softw. 2019;122:104519.

40. Arnold JG, Srinivasn R, Muttiah RS, Willians JR. Large area hydrologic modeling and assessment - part I: model development. J Am Water Resour Assoc. 1998;34(1):73-89.

41. Parton WJ, Hartman M, Ojima D, Schimel D. DAYCENT and its land surface submodel: description and testing. Global Planet Change. 1998;19:35-48.

42. Delgrosso S, Mosier A, Parton W, Ojima D. DAYCENT model analysis of past and contemporary soil $\mathrm{NO}$ and net greenhouse gas flux for major crops in the USA. Soil Tillage Res. 2005;83(1):9-24.
43. Wu Y, Liu S, Qiu L, Sun Y. SWAT-DayCent coupler: An integration tool for simultaneous hydro-biogeochemical modeling using SWAT and DayCent. Environ Model Softw. 2016;86:81-90.

44. Parton WJ, Schimel DS, Cole CV. A general model for soil organic matter dynamics: sensitivity to litter chemistry, texture and management In: Bryant RB, Arnold RW, editors. Quantitative modeling of soil forming processes. Madison: SSSA; 1994. p. 147-67.

45. Zhao F, Wu Y, Wang L, Liu S, Wei X, Xiao J, et al. Multi-environmental impacts of biofuel production in the U.S. Corn Belt: a coupled hydrobiogeochemical modeling approach. J Cleaner Prod. 2020;251:119561.

46. Moriasi DN, Arnold JG, Van Liew MW, Bingner RL, Harmel RD, Veith TL. Model evaluation guidelines for systematic quantification of accuracy in watershed simulations. Trans ASABE. 2007;50(3):885-900.

47. Hempel S, Frieler K, Warszawski L, Schewe J, Piontek F. A trendpreserving bias correction; the ISI-MIP approach. Earth System Dyn. 2013;4(2):219-36.

48. Ashraf Vaghefi S, Abbaspour N, Kamali B, Abbaspour KC. A toolkit for climate change analysis and pattern recognition for extreme weather conditions - Case study: California-Baja California Peninsula. Environ Model Softw. 2017:96:181-98.

49. Warszawski L, Frieler K, Huber V, Piontek F, Serdeczny O, Schewe J. The Inter-Sectoral Impact Model Intercomparison Project (ISI-MIP): project framework. Proc Natl Acad Sci USA. 2014;111(9):3228-32.

50. Yu CQ, Wang JW, Shen ZX, Fu G. Effects of experimental warming and increased precipitation on soil respiration in an alpine meadow in the Northern Tibetan Plateau. Sci Total Environ. 2019;647:1490-7.

51. Wang Y, Shao M, Liu Z, Warrington DN. Regional spatial pattern of deep soil water content and its influencing factors. Hydrol Sci J. 2012:57(2):265-81

52. Guo F-X, Wang Y-P, Hou T-T, Zhang L-S, Mu Y, Wu F. Variation of soil moisture and fine roots distribution adopts rainwater collection, infiltration promoting and soil anti-seepage system (RCIP-SA) in hilly apple orchard on the Loess Plateau of China. Agric Water Manag. 2021;244:106573

53. Liu Z, Ma P, Zhai B, Zhou J. Soil moisture decline and residual nitrate accumulation after converting cropland to apple orchard in a semiarid region: Evidence from the Loess Plateau. Catena. 2019;181:104080.

54. Zhang C, Wang Y, Jia X, Shao M, An Z. Variations in capacity and storage of plant-available water in deep profiles along a revegetation and precipitation gradient. J Hydrol. 2020;581:124401.

55. Ye L, Fang L, Shi Z, Deng L, Tan W. Spatio-temporal dynamics of soil moisture driven by 'Grain for Green' program on the Loess Plateau, China. Agr Ecosyst Environ. 2019;269:204-14.

56. Wang Y, Hu W, Zhu Y, Shao M, Xiao S, Zhang C. Vertical distribution and temporal stability of soil water in 21-m profiles under different land uses on the Loess Plateau in China. J Hydrol. 2015;527:543-54.

57. Tong $Y$, Wang Y, Song Y, Sun H, Xu Y. Spatiotemporal variations in deep soi moisture and its response to land-use shifts in the Wind-Water Erosion Crisscross Region in the Critical Zone of the Loess Plateau (2011-2015), China. Catena. 2020;193:104643.

58. Gao X, Li H, Zhao X, Ma W, Wu P. Identifying a suitable revegetation technique for soil restoration on water-limited and degraded land: considering both deep soil moisture deficit and soil organic carbon sequestration. Geoderma. 2018;319:61-9.

59. Feng Q, Yang L, Wang J, Shi X, Wang Y. Response of soil moisture and soil organic carbon to vegetation restoration in deep soil profiles in Loess Hilly Region. Acta Ecol Sin. 2019;39(18):6598-609.

60. Qian SS, King RS, Richardson CJ. Two statistical methods for the detection of environmental thresholds. Ecol Model. 2003;166(1):87-97.

61. Qiu J, Turner MG. Importance of landscape heterogeneity in sustaining hydrologic ecosystem services in an agricultural watershed. Ecosphere. 2015:6(11):art229.

62. Dang Y, Ren W, Tao B, Chen G, Lu C, Yang J, et al. Climate and land use controls on soil organic carbon in the loess plateau region of China. PLoS ONE. 2014;9(5):e95548.

63. Meyer RS, Cullen BR, Whetton PH, Robertson FA, Eckard RJ. Potential impacts of climate change on soil organic carbon and productivity in pastures of south eastern Australia. Agric Syst. 2018;167:34-46.

64. Mahecha MD, Reichstein M, Carvalhais N, Lasslop G, Lange H, Seneviratne $\mathrm{SI}$, et al. Global convergence in the temperature sensitivity of respiration at ecosystem level. Science. 2010;329(5993):838. 
65. Lu M, Zhou X, Yang Q, Li H, Luo Y, Fang C, et al. Responses of ecosystem carbon cycle to experimental warming: a meta-analysis. Ecology. 2013;94(3):726-38.

66. Shi Z, Thomey ML, Mowll W, Litvak M, Brunsell NA, Collins SL, et al. Differential effects of extreme drought on production and respiration: synthesis and modeling analysis. Biogeosciences. 2014;11(3):621-33.

67. Li G, Han H, Du Y, Hui D, Xia J, Niu S, et al. Effects of warming and increased precipitation on net ecosystem productivity: a long-term manipulative experiment in a semiarid grassland. Agric For Meteorol. 2017;232:359-66.

68. Humphrey V, Zscheischler J, Ciais P, Gudmundsson L, Sitch S, Seneviratne SI. Sensitivity of atmospheric $\mathrm{CO} 2$ growth rate to observed changes in terrestrial water storage. Nature. 2018;560(7720):628-31.

69. Cox PM, Betts RA, Jones CD, Spall SA, Totterdell IJ. Acceleration of global warming due to carbon-cycle feedbacks in a coupled climate model. Nature. 2000;408:184.

70. Jassal RS, Black TA, Novak MD, Gaumont-Guay D, Nesic Z. Effect of soil water stress on soil respiration and its temperature sensitivity in an 18-year-old temperate Douglas-fir stand. Glob Change Biol. 2008;14(6):1305-18.

71. Pacific VJ, McGlynn BL, Riveros-Iregui DA, Welsch DL, Epstein HE. Landscape structure, groundwater dynamics, and soil water content influence soil respiration across riparian-hillslope transitions in the Tenderfoot Creek Experimental Forest, Montana. Hydrol Process. 2011;25(5):811-27.

72. Liu L, Gudmundsson L, Hauser M, Qin D, Li S, Seneviratne SI. Soil moisture dominates dryness stress on ecosystem production globally. Nat Commun. 2020;11(1):4892

73. Sharp ED, Sullivan PF, Steltzer H, Csank AZ, Welker JM. Complex carbon cycle responses to multi-level warming and supplemental summer rain in the high Arctic. Glob Chang Biol. 2013;19(6):1780-92.
74. Kim J-S, Kug J-S, Jeong S-J, Huntzinger DN, Michalak AM, Schwalm CR, et al. Reduced North American terrestrial primary productivity linked to anomalous Arctic warming. Nat Geosci. 2017;10(8):572-6.

75. Albert KR, Ro-Poulsen H, Mikkelsen TN, Michelsen A, Van Der Linden L, Beier C. Effects of elevated $\mathrm{CO}(2)$, warming and drought episodes on plant carbon uptake in a temperate heath ecosystem are controlled by soil water status. Plant Cell Environ. 2011;34(7):1207-22.

76. Rey A, Oyonarte C, Morán-López T, Raimundo J, Pegoraro E. Changes in soil moisture predict soil carbon losses upon rewetting in a perennial semiarid steppe in SE Spain. Geoderma. 2017;287:135-46.

77. González-Ubierna S, Lai R. Modelling the effects of climate factors on soil respiration across Mediterranean ecosystems. J Arid Environ. 2019;165:46-54.

78. Niu F, Chen J, Xiong P, Wang Z, Zhang H, Xu B. Responses of soil respiration to rainfall pulses in a natural grassland community on the semi-arid Loess Plateau of China. CATENA. 2019;178:199-208.

79. Vicca S, Bahn M, Estiarte M, van Loon EE, Vargas R, Alberti G, et al. Can current moisture responses predict soil $\mathrm{CO} 2$ efflux under altered precipitation regimes? A synthesis of manipulation experiments. Biogeosciences. 2014;11(11):2991-3013.

80. Zhou X, Wan S, Luo Y. Source components and interannual variability of soil CO2efflux under experimental warming and clipping in a grassland ecosystem. Glob Change Biol. 2007;13:761-75.

\section{Publisher's Note}

Springer Nature remains neutral with regard to jurisdictional claims in published maps and institutional affiliations.
Ready to submit your research? Choose BMC and benefit from:

- fast, convenient online submission

- thorough peer review by experienced researchers in your field

- rapid publication on acceptance

- support for research data, including large and complex data types

- gold Open Access which fosters wider collaboration and increased citations

- maximum visibility for your research: over $100 \mathrm{M}$ website views per year

At BMC, research is always in progress.

Learn more biomedcentral.com/submissions 